\title{
Metabolic evaluation in patients with infected nephrolithiasis: Is it necessary?
}

\author{
Elisa Cicerello, Mario Mangano, Gian Davide Cova, Franco Merlo, Luigi Maccatrozzo \\ Unità Complessa di Urologia, Ospedale Ca'Foncello, Treviso, Italy.
}

\begin{abstract}
Summary Fifty-four patients with infected renal lithiasis underwent complete metabolic evaluation searching for underlying factors contributing to stone formation including urine analysis and culture. Metabolic abnormalities were significantly more present in patients with mixed infected stones (struvite+/-apatite and calcium oxalate) than in patients with pure infected stones (struvite+/-carbonate apatite): hypercalciuria in 40\%, hyperoxaluria in $34 \%$ and hyperuricosuria in $28 \%(p<0.05)$. Urinary excretion of citrate was low in both groups without statistically significant difference $(238+/-117 \mathrm{mg} / 24 \mathrm{~h}$ vs $214+/-104 \mathrm{mg} / 24 / \mathrm{h}, \mathrm{t}=0.72, p=0.5)$.

The few metabolic abnormalities present in patients with pure infected stones should suggest that urinary tract infection could change the urine chemistry in a lithogenic direction and be only cause of stone formation.
\end{abstract}

KEY WORDS: Pure infected nephrolithiasis; Mixed infected nephrolithiasis; Metabolic evaluation.

Submitted 1 June 2016; Accepted 31 August 2016

\section{INTRODUCTION}

Infected stones accounts for 10-30\% of all stones in various series $(1,2)$. If infected stones are present, it is difficult to eradicate infection because the stone may harbor the organism within its interstices. Even if sterilization of urine should be achieved by antibiotic therapy, reinfection could occur from bacteria harbored by residual stones. For this reason aggressive extirpative management is usually recommended. Although the gold standard of infected urolithiasis is the complete elimination of the stone, the need for complete metabolic evaluation of such cases has not often considered. Some authors have reported that metabolic anomalies, such as hypercalciuria, are present in greater than $50 \%$ of patients with infected renal calculi, while other authors have suggested that stone recurrence after complete elimination of infected stone is uncommon and therefore that metabolic evaluation should be not required (3-6).

Furthermore, there are differences in terminology: infected renal lithiasis may designate staghorn stones which may have a variety of composition, urolithiasis secondary to urea-splitting bacteria (struvite and/or carbonate apatite) or calcium oxalate calculi that have been secondarily infected $(3,5,6-9)$.
In despite of the terminology, stone rate of regrowth and/or recurrence in patients with infected nephrolithiasis is high and specific measures preventing stone formation are mandatory.

In an effort to clarify the problem of infected nephrolithiasis we reviewed our experience with the metabolic evaluation of patients whose stone analyses reveals the presence of struvite and/or carbonate apatite.

\section{Materials AND METHOdS}

For the aim of this study we considered 54 patients with infected renal lithiasis who underwent procedures for stone removal between January 1995 to December 2008 in the Urologic Unit of Treviso General Hospital. Based on the composition of stones or small fragments removed, 19 patients had pure struvite +/-apatite and 35 mixed stones (struvite +/-apatite and calcium oxalate). Other types of stone materials were excluded. The mean age of patients was 45 years with a range of 18 to 76 years. There were 33 females and 21 males. All patients underwent a thorough history and physical examination; chemical stone analysis (Ecoline Diasys Diagnostic Systems, GMH) and complete metabolic evaluation: twenty-four urine sample was analysed for levels of calcium, oxalate, uric acid, citrate, magnesium and phosphate. After at least 12 hours fasting venous blood was analysed for calcium, phosphate, uric acid and creatinine; morning spot urine was collected for urine analysis and culture. KUB X-ray and/or kidney ultrasound were performed from one to three months after the urological procedures for stone removal. Intravenous urography and/or computed tomography scan were done when we considered to investigate anatomy of the urinary tract.

Long-term follow-up information was recorded, with emphasis on recurrence of stone formation and urinary infection. Chi-square test was performed to compare the percentage of metabolic abnormalities in the two groups. A paired t-test was used to compare the results of 24hour urine data in the different groups.

\section{RESULTS}

All patients required surgical intervention for their stone disease. Thirty-three patients underwent nephrostolithotomy (PCNL) with or without shock wave lithotripsy 
(SWL) and eleven were primarily treated by SWL alone. KUB X-ray carried out from one to three months after treatment showed that 39 patients were stone-free and 15 had residual fragments clinically insignificant (less than $5 \mathrm{~mm}$ in diameter). All patients with pure infected stone had risk factors for chronic urinary infections (neurogenic bladder, urinary ileal diversion and urinary tract anomalies). Patients with mixed stones were likely to have previous urolithiasis or a positive family history of urolithiasis (Table 1).

Positive urine cultures pretreatment were present in 41 patients, in 17 with pure infected stones and in 24 with mixed stones. Escherichia coli was present in $67 \%$ of patients with mixed infected stones and Proteus in 47\% with pure infected stones. Patients with pure struvite stones have more infecting organisms than patients with mixed stones (Table 2).

The results of 24-hour urine studies are listed in Table 3. The urinary calcium, oxalate and uric acid excretion in mixed stone patients was higher than in those with pure infected stones. Hypercalciuria was present in $40 \%$ of mixed infected patients (chi-square $=4.19 \mathrm{p}<0.05$ ), hyperoxaluria in $34 \%$ (chi-square $=7.37, \mathrm{p}<0.01$ ) and hyperuricosuria in $28 \%$ (chi-square $=4.90, \mathrm{p}<0.05$ ) . Four patients with mixed stones were hypercalciuric and hyperuricosuric. Of the patients with pure struvite only 2 were hypercalciuric and one hyperoxaluric. Urinary excretion of citrate was low in both groups

\begin{tabular}{|lcc|}
\hline & Pure struvite $(\mathbf{n}=\mathbf{1 9})$ & Mixed stones $(\mathbf{n}=\mathbf{3 5})$ \\
\hline Females & $11(58 \%)$ & $23(66 \%)$ \\
\hline Family history of stones & $2(11 \%)$ & $12(34 \%)$ \\
\hline Previous stones & $10(53 \%)$ & $25(71 \%)$ \\
\hline Previous UTI & $14(74 \%)$ & $20(29 \%)$ \\
\hline Neurogenic bladder & $12(63 \%)$ & 0 \\
\hline Ileal urinary diversion & $2(11 \%)$ & 0 \\
\hline Urinary tract anomalies & $5(26 \%)$ & 0 \\
\hline
\end{tabular}

Table 1.

Risk factors according to stone analysis.

\begin{tabular}{|lcc|}
\hline & Mixed infected stones (35) & Pure infected stones(19) \\
\hline Escherichia coli & $16(67 \%)$ & $3(16 \%)$ \\
\hline Proteus mirabilis & $2(6 \%)$ & $9(47 \%)$ \\
\hline Klebsiella pneumoniae & $3(9 \%)$ & $2(11 \%)$ \\
\hline Enterococci & $1(3 \%)$ & $2(11 \%)$ \\
\hline Mixed (more than one strain) & $2(6 \%)$ & $1(5 \%)$ \\
\hline
\end{tabular}

Table 2.

Comparison between the results of pretreatment urine cultures in mixed and pure infected stones.

\begin{tabular}{|lcccccc|}
\hline & Calcium & 0xalate & Uric acid & Citrate & Magnesium & Phosphate \\
Mixed stones & $302 \pm 98$ & $33 \pm 12$ & $603 \pm 207$ & $238 \pm 117$ & $66 \pm 91$ & $832 \pm 395$ \\
\hline Struvite \pm carbonate epatite & $143 \pm 87^{*}$ & $17 \pm 6.9 *$ & $396 \pm 102^{*}$ & $214 \pm 104^{* *}$ & $78 \pm 33^{* *}$ & $723 \pm 320^{* *}$ \\
\hline$* p<0.001 ; * *$ n.s. & & & & & & \\
\hline
\end{tabular}

Table 3.

Urinary parameters $(\mathrm{mg} / 24 \mathrm{~h})$ without statically significant difference (238+/-117 $\mathrm{mg} / 24 \mathrm{~h}$ vs $214+/-104 \mathrm{mg} 24 / \mathrm{h}, \mathrm{t}=0.72, \mathrm{p}=0.5)$. No patient was hypercalcemic or had primary hyperparathiroidism.

The mean of follow-up was 42+/-68 months and despite efforts at stone prevention, both urinary infections and stones were recurrent. All patients received antibiotic profilaxis for long time. Patients with mixed stones received also specific medical treatment according to metabolic abnormalities (thiazides, potassium citrate or allopurinol) for long time.

In the pure struvite group of 19 patients, 12 had recurrent infection and 9 developed new calculi. In the mixed stone group of 35 patients, 18 had recurrent infection, while new calculi occurred in 11 patients. Further procedures for stone treatment were required in 5 patients in the pure struvite group and in 6 patients in the mixed group.

\section{Discussion}

The formation of struvite and/or carbonate apatite stones depends on ureolysis in the presence of urease-splitting bacteria. Ammonia and carbon dioxide are transformed in ammonium and bicarbonate whose subsequent binding with available urinary cations produces magnesium ammonium phosphate (struvite) and carbonate apatite. This way could be the primary cause of stone formation in those patients with pure infected stones (1).

However, it has been previously reported that an infection with urease producing bacteria is not present in all patients with struvite+/-apatite stones (10). Since a responsible bacteria cannot always be cultured from voided urine an explanation for the discrepancy is that only urine samples and not stones have been cultured (11). Another tentative explanation is that the responsible urease-producing bacteria have not been detected. Ureoplasma urealyticum and certain urease-producing Corynebacteria are missed if only cultures with conventional tecniques are performed (12). Also in our study only routine urine analysis and culture on morning spot urine were performed.

Calculi usually referred to as metabolic stones (that is stones composed of calcium oxalate, calcium phosphate or uric acid) also frequently associated with urinary tract infections, mostly non-urease producing bacteria. The infection then is considered to be secondary to the stone and not involved in the stone formation (10). However, there are several mechanisms by which non urease splitting bacteria could enhance the formation of urinary tract calculi. Thus, Escherichia coli have been showed to act as nucleus for the deposition of crystals and to change the urine chemistry in a lithogenic direction (13). Other uropathogenic microorganisms have also been shown in experimental studies to damage the mucous coat with an increased adhesion of crystals to the uroepitelium as the results. In our study, where urinary infection was present in 69\% 
of patients with mixed stones, metabolic anomalies (hypercalciuria, hyperoxaluria and hyperuricosuria) could increase the adhesion of crystals to damaged uroepithelium and promote stone formation.

More recently, it has been reported that been that Escherichia coli may be related to stone formation by the capacity of bacteria to form biofilm (14). Biofilm can promote persistence in the urinary tract and on biomaterial of the devices, protecting bacteria from the clearing effect of hydrodynamic forces and the killing activity of the host defence mechanism and antibiotics.

Furthermore, nanobacteria have been reported to cause stone disease. Nanobacteria are micro-organisms that are 10-100 times smaller than normal bacteria. They may released from the stone during the treatment and create nidi for the formation of stones (15). Endotoxins are another factor supposed involved in the pathogenesis of urinary infection from renal stone. Also these have been released in the systemic circulation during stone treatment, inducing an inflammatory response. The process is apparently amplified in the presence of obstructive uropathy, due to increased permeability of blood and lymphatic vessels of the renal pelvis (16).

Our data demonstrate that patients with mixed stones (calcium oxalate plus struvite and /or carbonate apatite) have different metabolic characteristic compared to patients with pure struvite. The presence of hypercalciuria, hyperoxaluria and hyperuricosuria are similar to those observed in our group of idiopathic stone formers (17). Indeed the presence of mixed infected calcium stones, such us calcium oxalate plus struvite appears to be a marker for underlying metabolic abnormalities and emphasizes the need for complete metabolic evaluation of these patients.

Pure infected stones are caused by a chronic bacteriuria (such as in patients with a neurogenic bladder, urinary diversion or anomalies of urinary tract), while metabolic anomalies were present only in 3 patients (in 2 hypercalciuria and in 1 hyperoxaluria). The presence of hypocitraturia in both groups could be due to the degradation of urinary citrate by bacterial enzymes from infection (18). Consequently, even in the absence of stone material for analysis, renal stones in this subset of patients could be assumed to be pure infected in nature, and metabolic evaluation will likely be unrewarding. Efforts should be directed at the complete eradication of the stone material and of any urea-splitting organism identified.

High rates of recurrent infection and recurrent stone formation in both pure and mixed infected stones have been observed. The need for retreatment was high and emphasizes the need for careful follow-up of such patients. Antibiotic therapy could decrease bacteriuria, but the persistence of stone or residual fragments or sand compromises the possibility of eradication the infection. Persisting urinary tract infection could increase the risk of stone recurrence. Urease inibitors could be theoretically used in the treatment of infected nephrolithiasis. Besides collateral effects and their low effectiveness, they are little used $(19,20)$. Currently long-term antibiotic therapy is advised in patients with infected stones. Antibiotic therapy can reduce the bac- terial load significantly, although urine does not become sterile (21). Besides contrasting septic risks, antibiotic therapy reduces recurrence or regrowth of stone after urologic procedures. In patients with mixed infected stones also adequate medical treatment is required, as already reported in previously studies (22).

Further prospective trials are necessary to confirm this observation.

\section{Conclusions}

Patients with mixed infected nephrolithiasis show different and metabolic characterics compared to patients with pure infected stones. The infected lithiasis in these patients probably comes to top of metabolic abnormalities present in idiopatic stone formers. Conversely, complete metabolic evaluation of patients with pure infected lithiasis should be not necessary. Hypocitraturia, in this group of patients, could be due the presence of chronic urinary infection. Patients with mixed infected stones could be benefit not only from the usual antibiotic therapy, but also from specific therapies for the underlying metabolic abnormalities.

\section{REFERENCES}

1. Griffith DP, Osborne CA. Infection (urease) stones. Min Electrolyte Metab. 1987; 13:278-285.

2. Bichler KH, Eipper E, Naber K, et al. Urinary infection stones. Int J Antimicrob Agents. 2002; 19:488-498.

3. Resnick MI, Boyce WH. Bilateral staghorn calculi: patient evaluation and management. J Urol. 1980; 123:338-341.

4. Smith LH. Renal lithiasis and infection. In: Thomas WC Jr (ed): Renal Calculi: A Guide to Management. Sprinfield, IL: Charles C Thomas, 1976, chapter 12.

5. Segura JW, Erickson SB, Wilson DM, et al. Infected renal lithiasis: results of long-term surgical and medical management. In: Smith LH, Robertson WG, Finlayson B (eds): Urolithiasis: Clinical and Basic Research. New York: Plenum Press. 1981; pp. 195-198.

6. Silverman DE, Stamey TA. Management of infection stones: the Stanford Experience Medicine. 1983; 62:44-51.

7. Griffith DP. Struvite stones. Kidney Int. 1978; 13:372-382.

8. Miano R, Germani S, Vespasiani G. Stones and urinary tract infection. Urol Int (Suppl 1) 2007; 32-36.

9. Streem SB, Lammert C. Long term efficacy of combination therapy for struvite staghorn calculi. J Urol. 1992; 147:563-566.

10. Hugosson J, Grenabo L, Hedelin H, et al. Bacteriology of upper urinary tract stones. J Urol. 1990: 143:965-968.

11. Mariappan P, Smith G, Bariol SV, et al. Stone and pelvic urine culture and sensitivity are better than bladder urine as predictors of urosepsis following percutaneous nephrolithotomy: a prospective clinical study. J Urol. 2005; 173:1610-1614.

12. Hedelin H, Brorson J, Grenabo L, Pettersson S. Ureaplasm urealitycum and upper urinary tract stones. Brit J Urol. 1984; 56:244249.

13. Djojodimirdio T, Soebadi DM, Sotjipto. Escherichia Coli infection induces mucosal damage and expression of proteins promoting urinary infection. Urolithiasis 2013; 41:295-301. 
14. Holmgren K. Urinary calculi and urinary tract infection. A clinical and microbiological study. Scand J Urol Nephrol (Suppl. 98.) 1986; 98:1-71.

15. Kajender EO, Cifticioglu N. Nanobacteria: an mechanism for pathogenic intra and extracellular calcification and stone formation, Proc Nal Acad Sci USA. 1998; 95:8274-8279.

16. McAleer I, Kaplan GW, Bradley JS, et al. Endotoxin content in the renal calculi. J Urol. 2003; 169:1813-1814.

17. Cicerello E, Merlo F, Maccatrozzo L. Nephrolithiasis in Medulary Sponge Kidney. Arch Ital Urol Androl. 2011; 83:40-42.

18. Cicerello E, Merlo F, Maccatrozzo L. Metabolic evaluation of infected nephrolithiasis. Eur Urol. 2009; 8 (Suppl. 3):S205.

19. Griffith DP, Gleesen MJ, Lee H, et al. Randomized double -bind trial of Lithostat (acetohydroxamic acid) in the palliative treatment of infection-induced urinary calculi. Eur Urol. 1991; 20:243-247.

20. Iqbal MW, Youssef RF, Neisius A, et al. Contemporary management of struivite stones using combined endourological and medical tratament: predictors of unfavorable clinical outcome. J Endourol. 2013; 28:1-7.

21. Cicerello E, Merlo F, Gambaro G, et al. Effect of alkaline theraphy on clearance of residual stone fragments after shock wave lithotripsy in sterile and calcium nephrolithiasis patients. J Urol. 1994; 15:5-9.

22. Sun BY, Lee YH, Jiaan BP, et al. Recurrence rate and risk factors for urinary calculi after shock wave lithotripsy. J Urol. 1996; 156:903-906.

\section{Correspondence}

Elisa Cicerello, MD (Corresponding Author)

elisa.cicerello@tin.it

Mario Mangano, MD

m.mangano@ulss.tv.it

Gian Davide Cova, MD

gd.cova@ulss.tv.it

Franco Merlo, MD

f.merlo@ulss.tv.it

Luigi Maccatrozzo, MD

1.maccatrozzo@tv.it

Unità Complessa di Urologia, Ospedale Ca’Foncello

Piazza Ospedale -31100 Treviso, Italy 